\title{
Research of Current Situations and Problems of Calligraphy Education in Rural Primary and Middle Schools \\ -Take Huanggang as an Example
}

\author{
Zuo Guohua ${ }^{1, a}$
}

${ }^{1}$ Fine Arts Institute of Huanggang Normal University, 438000

aemail,

Key Words: Calligraphy Education, Teachers Forces, Teaching Evaluation

\begin{abstract}
This paper briefly elaborates the histories and current situations of calligraphy education in our domestic rural primary and middle schools, elaborates various problems existing in calligraphy education of rural middle and primary schools of Huanggang City from five aspects of calligraphy teaching materials, teaching hardware, teachers forces, propaganda forces of social public opinions and teaching evaluation system, and proposes solutions particularly. In this paper, it adopts the measurement method to investigate and analyze teachers forces, hardware facilities, assessment standards and other aspects of the calligraphy education in rural areas of Huanggang city and obtains the conclusion: the emphasis of municipal local governmental departments, schools and parents on rural calligraphy education is not enough, numerous calligraphy courses opened up by rural schools just exist in name only, enhancing the inputs of hardware facilities, fastening the construction of teaching materials and the step of teachers team construction, and establishing the complete assessment system is imperative.
\end{abstract}

\section{Introduction}

This paper is the project subject of "the $12^{\text {th }}$ five-year-plan"of Hubei education science in the year of 2013, the topic name: Research of Calligraphy Education Problems in Rural Middle and Primary Schools of Huanggang City Based on "New Curriculum Standards”, subject code: 2013B188

Hubei Province Education Department Humanity Society Scientific Research Project of 2014, project name: Research of Calligraphy Education problems in Rural Middle and Primary schools of Huanggang City and its Countermeasures, project code: 14Q117

In the early period of $20^{\text {th }}$ century, Tao Xingzhi,Yan Yangchu,Liang Shuming, Huang Yanpei and a batch of educators started focusing on our domestic rural education, and advocated "rural education"ideological trend and movement. It further discusses the selection and cultivation of village teachers. In 1988, Teaching Research Institute of Nanjing Normal University compiled the national first edition teaching material Rural Education. It briefly elaborates the basic theories, current situations, scientific research, management problems, etc of our domestic rural education in the new period, and introduces the rural education in the developed countries. Because of histories, economics and other reasons, they cannot regard calligraphy education as a special subject for research, but these achievements by predecessors have laid the theoretical foundation for the subsequent development of calligraphy education.

In the 1990s, Education Department started focusing on the writing teaching in middle and primary schools. In recent years, Education Department issued a series of documents, and proposed corresponding requirements. Especially in 2002, Education Department announced the new curriculum standards in the compulsory education period, and proposed specific requirements on the calligraphy teaching missions in each period of primary and middle schools. 
Under the call of Education Ministry, most of national provinces and cities have positively responded to the promotion of calligraphy education and inherited excellent national culture system. In middle and primary schools, calligraphy education lessons are gradually developed in primary and middle schools, and the development situations vary greatly in accordance with different local actual situations in each province. In "big calligraphy province" and separate economic developed cities, partial prosperity of calligraphy education is in urban schools, and most part of rural areas are left out because of the lack of teachers and teaching materials and other realistic reasons. The emphasis of parents and students on the development of calligraphy education in middle and primary schools is far from enough, especially in rural area, this problem appears to be very incisive. The school's promotion of calligraphy education in middle school and primary school is worrying. However, at present, researchers are lacked of the development of site investigation and case research on the calligraphy education in middle and primary schools of rural areas, no specific data reflects such difference between cities and villages.

For theoretical research based on primary and middle school calligraphy education, Capital Normal University gave the example. This university established "Primary and Middle School Calligraphy Education Research Center" on December $27^{\text {th }}$ of December, integrates the calligraphy education resources of calligraphy culture research institute, literature college and primary education college of this school, strives for the theoretical research on calligraphy basic education, and constructs the calligraphy education teaching theoretical framework in primary and middle schools. Besides, some scholars also published academic articles in such aspect in the past few years: in 2009, in the paper Research of Current Situation Investigation and Countermeasures of Calligraphy Education in Middle and Primary Schools of Hunan Province by Zheng Xin'an, some specific countermeasures were put forward on the education of calligraphy crisis from teaching meaning, method, cultivation means, and teaching material compositions. In 2011, in master paper Research of Current Situation Investigation of Calligraphy Education in Middle and Primary Schools of Shandong Province and its Countermeasures by Qin Sishuai, it took Shandong China calligraphy and painting art level exam and the questionnaire of the calligraphy education in ten middle and primary schools of Wulian County as the example, and demonstrated the necessity and urgency of fastening the calligraphy education on middle and primary school students in Shandong Province. In 2012, the master paper Current Situations and Thinking of Calligraphy Education in Middle and Primary Schools by Hou Lihong, it is stood on the investigative results of current situations of calligraphy education in primary and middle schools of Wuhan City, summarized and analyzed problems existing in calligraphy education of primary and middle schools from this part of samples, so as to analyze the causes of these problems and put forward corresponding countermeasures.

This research emphasizes on the thinking of current situations and countermeasures of calligraphy education in urban schools, lacks the discussion on the special subjects in rural schools. The $18^{\text {th }}$ Meeting reports put forward that it should develop education in advance, vigorously promote the education level, reasonably allocate education resources, and emphatically incline to rural, remote, poor and national regions. As the famous basic education village in the nation, as well as the school concentration area in the rural areas with weak economic foundations, research of this subject equips with realistic and profound meaning to improve the basic education quality, which provides theoretical basis of calligraphy education in national middle and primary schools as well.

Huanggang city, as the hometown of basic education, belongs to revolutionary old area, its economy is relative lagged behind, 11 administrated counties, six of them are national and provincial poor counties. In the whole city, there are 1384 middle and primary schools. According 
to the statistics of Yingshan Education Bureau, two large scale middle and primary school layout adjustment has been done after "universal nine-year compulsory education” in Yingshan County. Until May of 2012, this county totally involves 124 middle and primary schools, less than 37\% of them have opened up calligraphy lessons, among 2844 full-time teachers in primary and middle schools, less than $2.3 \%$ of them are engaged in calligraphy education, among 32008 students, less than $53 \%$ of them have participated in calligraphy lessons. Among 22 ordinary middle schools, less than 23 of then have opened up calligraphy lessons; among 1569 middle school teachers, less than $1.5 \%$ of them have taught calligraphy lessons, and among 23783 students, less than $21 \%$ of them have had calligraphy lesson. From this data, it can be seen that the foundation of calligraphy education is weak in most part of rural areas in Huanggang city, the following problems are existing mainly.

\section{Reasonable and Professional Calligraphy Teaching Materials Are Expected, Calligraphy Teaching Mode Is Single}

At present calligraphy education in rural primary and secondary schools lacks of teachers and teaching hardware facilities investment. Accompanying this is the weakness of teaching material construction that can't reflect the characteristics of contemporary calligraphy. The existing calligraphy teaching materials of primary and secondary schools can't well represent all and unique characteristics of calligraphy discipline, neither in the guiding ideology and the content, nor in the format. Blindly sticking to such outdated materials as a traditional copybook for calligraphy or several calligraphers' models will undoubtedly lead to a rigid teaching mode. Currently, Hubei Province had adopted two sets of writing teaching materials for school. But "writing” teaching materials and "calligraphy" teaching materials are different in the educational significance and training objectives. "Writing” teaching material can't fully reflect objectives and requirements of textbook compilation of the artistic lesson. Nor does it show the artistic features and educational function in sentiment of calligraphy discipline.

The current teaching methods are too obsolete for calligraphy lesson in rural primary and secondary schools in Huanggang. Since most teachers have not received professional theory and skill training, classes are sheep-like. Teachers make less explanation and the explanation lacks of theoretical knowledge. Some teachers repeat what the textbook and copybook for calligraphy say without adding their own understanding. Therefore, they impart the knowledge in a very stiff way and they can not flexibly combine theoretical explanation and skill training.

\section{Schools' Teaching Hardware Facilities Are Inadequate and Teaching Resources for Calligraphy Are Insufficient}

Basic education in our country adopts local responsibility and multi-level management. County and town governments have public finance difficulties, especially counties and towns in some poverty-stricken areas. They have to bear the heavy responsibility of financing basic education, resulting in minimal financial allocations for basic education in rural areas.

Since junior high school in rural area is relatively small, school funding is tight, the school allocates more funding in key disciplines. As a second-rate curriculum, calligraphy can not share school's favor in capital investment. According to the survey, most schools have no special calligraphy classroom and the teaching aids in quantity and quality is also limited, which, to some extent, limits calligraphy teaching in schools. Lack of students calligraphy activities is also an important reason for unsatisfactory teaching situations. 
Rural primary schools are a little better than junior high schools in calligraphy. Some schools arrange a certain amount of handwriting classes and prepare some copybooks and textbooks. But overall, the funding is not enough and calligraphy activities are often limited because of lack of funding. It is difficult for limited class teaching to meet students' positive psychological characteristics.

Shortage of school's teaching resources has a direct impact on classroom teaching. Serious deficiencies of teaching books, teaching aids, pictures and so on for calligraphy has bad influence on the performance of teachers' abilities and expansion of students' horizons.

In recent years, due to the government's attention, teaching hardware facilities in rural schools have been improved and calligraphy teaching resources have also been increased. In 2006, according to the new village construction planning, the city's education department started boarding school construction and Mingde project. Till the end of the year, the whole city completed 28 boarding construction projects and 14 Mingde projects and totally invested 24.65 million yuan and finished 47,000 square meters of building areas. The city government organized three counties Wuxue, Huangmei and Qichun to combat the earthquake and do relief work and recover the schools. These three counties were invested nearly 10 million yuan and completed 28 reconstruction projects with building areas of 18,000 square meters. They finished of 87 modification and expansion projects with building areas of 4.9 square meters and total cleared more than 60,000 square meters of dilapidated buildings. The government made a statistical survey of debt in nine-year compulsory education and high schools and the city had debt of 274 million yuan in compulsory education. In April 2013, Huanggang Language Commission and City Board of Education launched work of standard creation and selection for "schools of calligraphy teaching characteristics”. Through building and selecting "schools of calligraphy teaching characteristics”, the city government explored effective ways and long-term mechanism for calligraphy education, promoted advanced experiences, gradually expanded the demonstration results and made an effort to promote a solid and effective calligraphy education. This became a highlight in the city's education and language work.

\section{Weak Calligraphy Teachers Team, Worrying Prospects}

China Education Reform and Development Outline points out, education is the hope of revitalizing the nations, and teachers are the hope of revitalizing education. ${ }^{\mathbf{2} \mathbf{I}}$ Teaching and learning are the two cores of school education. For students, teachers are very important. As Han Yu said in On Teachers: "A teacher is one who passes on the truth, imparts knowledge and solves puzzles", he emphasized the important role teachers should play in the teaching process. A teacher not only need a strong professionalism, but also have good humanistic quality. If a teacher knows little or nothing about the subject he teaches, he will seriously affect the normal classroom teaching of calligraphy. At present, most teachers for calligraphy lesson in rural primary and secondary schools are part-time teachers. The messy staff themselves lack of basic theoretical training and solid writing skills and muddle through the teaching. This leads to simplification of class teaching and students will feel tired of the calligraphy lesson as time passes.

By conducting sample investigation on 23 schools of Huanggang city, the author discovers that very few of calligraphy teachers in rural primary and middle school teachers have not received the standard calligraphy education of normal colleges, their writing skills are limited, their knowledge of calligraphy is little, so teaching demonstration is very grudging, difficult to infuse correct knowledge to students, teachers are also like this, how can they spread such old traditional art? 


\section{Weak Social Opinion Propaganda Force, Low Emphasis Degree of Parents And Students}

I investigated Huangmei County Tingqian Town Center School and interviewed partial parents and students, understood that the ordinary recognition level of primary and middle school students on calligraphy study is not enough. A lot of students believe that it is quite enough to write strokes so that characters are easy to recognize, even some students believe that they can use the computer to type characters, handwriting has not become so important. The emphasis degree of partial parents is not high, and believe that children can learn main lessons well and pass the exam, regardless of beautiful characters. Only very few partial parents believe that writing beautiful characters can cultivate their personalty and decorate "facade". Students and parents have not paid enough attention on writing, so is the entire society, schools also want to make calligraphy teaching well, but their strength cannot match their ambition. I made the superficial analysis on the education current situation of rural middle and primary schools in the region, and proposed corresponding advice and countermeasures for existing problems.

\section{Incomplete Assessment Standards and Teaching Evaluation System}

By delivering 100 copies of questionnaires to 37 schools in Macheng, Huangmei, Yingshan, Wuxue, results show that $65 \%$ of rural primary and middle schools in this city have not established calligraphy assessment standards and teaching evaluation systems, 5\% of the schools have established calligraphy assessment standards, and 30\% of schools express that they are preparing to establish calligraphy assessment standards and teaching assessment system. Calligraphy education assessment standards make calligraphy education ordered and evidence-based, make teaching targets more specific and teaching order more stable. Establishing standard and ordered calligraphy education assessment standards is very necessary. Calligraphy education assessment is beneficial to guiding student's interest on calligraphy learning, and diversified evaluation methods can be attempted. ${ }^{\mathbf{2} 2}$ Establishing the scientific and complete teaching evaluation system can reveal the advantages and disadvantages in calligraphy teaching, so as to adopt positive and effective countermeasures for problems existing in the teaching. At present, in this region, middle and primary schools are enhancing the system construction in the aspect of calligraphy education, and some new policies have been issued in the aspect of calligraphy education management. For example, in June $3^{\text {rd }}$ of this year, Wuxue Meichuan Town Primary School conducted the further planning and arrangement in the aspect of calligraphy teaching management, teachers manning, established Calligraphy Education Implementation Solutions In Meichuan Town Primary School, developed calligraphy education activity efficiently.

In summary, calligraphy education in rural middle and primary schools of Huanggang City still exists various deficiencies, each school should emphasize on calligraphy education and open up special calligraphy lessons necessarily, and penetrate calligraphy education into Chinese teaching, establish corresponding teachers team construction plans, arrange calligraphy teachers for further study in the plan and order, improve the basic technique and theoretical qualification of calligraphy teachers, developed multiple forms of classes and make extracurricular teaching very necessary. In the meantime, they also develop the interest of students, improve their abilities of admiration and aesthetics, make them feel the sense of being a person and doing things and nurture them with aesthetics and morality from calligraphy education.

\section{References:}

[1] Yu Xiangyang, Primary Exploration on Current Situation Investigation and Countermeasure of 
Calligraphy Education in Rural Primary Schools [J] Teachers. May, 2012

[2] Ning Tong, Research of Teachers Team Construction Problems in Rural Primary and Middle Schools of Shanxi Province [D] Shanxi University of Finance and Economics. March of 2013 